\title{
El desarrollo del libro álbum en Colombia: 1970 - 2008
}

\author{
Zully Pardo
}

El libro álbum es uno de los géneros más destacados de la literatura infantil contemporánea $^{1}$. Aunque erróneamente ha sido definido por el formato y las ilustraciones, especialistas en este tema consideran que va más allá de la materialidad, involucrando elementos comunicativos y semióticos.

Este género, propio de la literatura infantil, se basa en el principio de que la ilustración y el texto deben formar parte de un todo narrativo, fusionando el papel del ilustrador y del autor. La estructura secuencial de sus páginas, el ritmo y la preponderancia de las imágenes juegan un papel fundamental a tal punto que, siempre que haya narratividad, pueden existir álbumes sin palabras, con historias creadas a partir de las imágenes. Además, el libro álbum tiene un cariz lúdico de experimentación artística - que deriva del ingenio de su contenido - de ahí proviene su ubicación como producto cultural emblemático de la posmodernidad.

De acuerdo con Silva-Díaz (2006) un libro álbum se caracteriza por la preponderancia de imágenes, así como por la confluencia de dos códigos: el léxico y el visual que, además de contemplar las ilustraciones, contempla el diseño, la tipografía y el soporte. Complementando esta idea, Fanuel Díaz afirma que:

El libro álbum se reconoce porque las imágenes ocupan un espacio importante en la superficie de la página; ellas dominan el espacio visual, [...] existe un diálogo entre el texto y las ilustraciones [...] En los libros álbum no basta con que exista esta interconexión de códigos. Debe prevalecer tal dependencia que los textos no puedan ser entendidos sin las imágenes y viceversa. (2007: 92-93)

Colomer (2002), además, reconoce la presencia de un lector adulto como mediador, y de la oralidad y el tiempo de lectura como vehículos para la construcción de sentido. Para ella, tanto texto como imagen pueden tener muchas funciones: "contar, subrayar, desmentir, caracterizar, imprimir un tono, crear una atmósfera o insertar un punto de vista nuevo en la narración" (2002: 20-21).

La experiencia de lectura del libro álbum es amplia dados los códigos que interactúan para producir los significados: un código simplifica o complica lo que el otro sostiene. Así, al efectuar dos tipos de lectura paralelamente, el lector siente la necesidad de releer el libro para percibir todos los significados posibles. 


\section{Precursores del libro álbum en Colombia}

El desarrollo del libro álbum en Colombia fue tardío en comparación con otros países latinoamericanos. Las causas se relacionan con las condiciones sociales, culturales y políticas de un país que ha estado en guerra constante durante más de cincuenta años. Fue a partir de la década de 1930 cuando los niños empezaron a ser considerados seres sociales distintos de los adultos y dignos receptores de publicaciones exclusivas para ellos.

Antes de la aparición de los auténticos álbumes colombianos, tres libros editados, escritos e ilustrados por colombianos - pueden ser considerados precursores del libro álbum en este país.

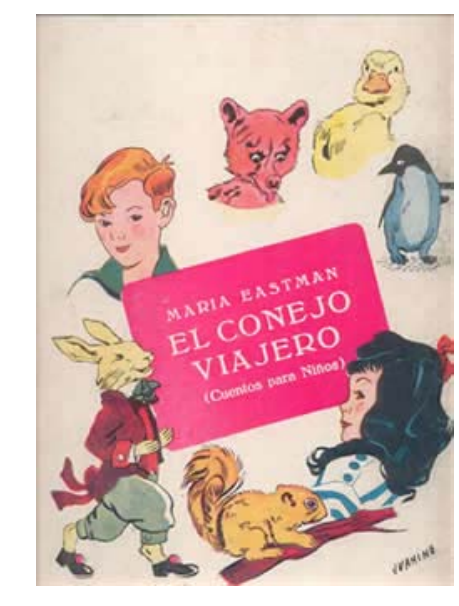

(C) J. Renalu. Del libro El conejo viajero, de M. Eastman (texto) y, J. Renal (il.), Bogotá: Ed. de 1 a Universidad Nacional, 1948 (portada).

El Conejo Viajero de María Eastman fue el primer libro ilustrado en gran formato $(32 \times 25 \mathrm{~cm}$.) de la literatura infantil colombiana. Con influencia de Beatrix Potter, este libro tiene un alto componente de ilustraciones de autoría de personalidades de la plástica colombiana. Es cuidadoso en la distribución gráfica, aunque no siempre acierta con el binomio imagen-texto.

En 1967 Oswaldo Díaz publicó el libro Cuentos tricolores. Allí las ilustraciones de Trujillo Magnenat, los textos de Díaz y la edición de Lerner dan un importante giro al libro ilustrado para niños en Colombia. Los cuentos que integran esta obra van más allá de los fines didácticos, son obras literarias de importante valor estético. Trujillo Magnenat, a diferencia de otros maestros de la plástica en Colombia, reconoció su país 
y lo plasmó en su obra, dándole un carácter muy local pero a la vez amplio y próximo a los lectores colombianos.

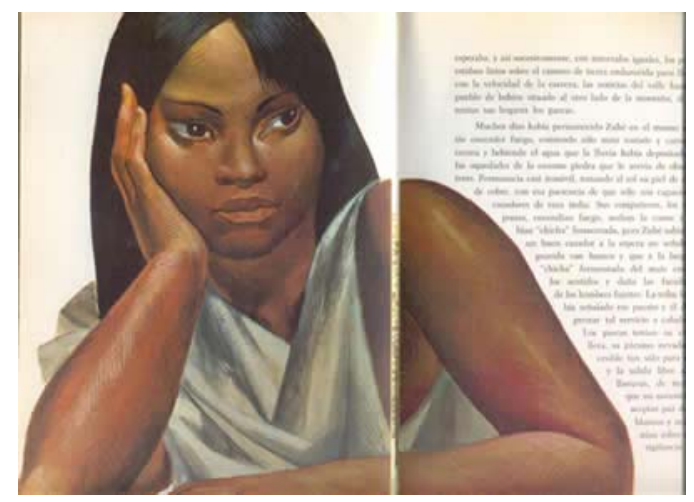

(C) S.Trujillo Magnenat. Del libro Cuentos Tricolores, de O. Díaz (textos) y S. Trujillo Magnenat (il.), Bogotá: Ediciones Lerner Juveniles, 1967.

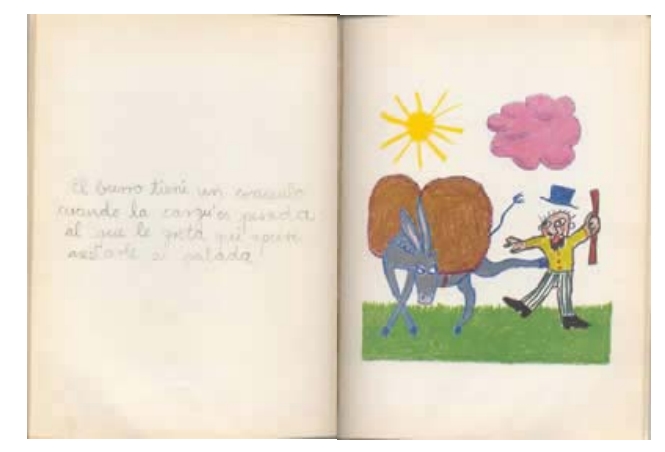

(C) L.Jaramillo. Del libro Qué bonito baila el chulo, de M.

Fornaguera (textos) y L. Jaramillo (il.), Bogotá: Carlos Valencia Ed.. 1980 .

Qué bonito baila el chulo (1980), ilustrado por el artista Lorenzo Jaramillo y con coplas compiladas por María Fornaguera, es un libro de gran formato $(32 \times 25 \mathrm{~cm}$.) y tapa dura en el que se destaca el inusual manejo de los espacios en blanco. Con este libro se empezó a considerar conscientemente el valor del texto, su tipografía y su ubicación en la página en relación con la ubicación de la imagen y el sentido que ésta quiere expresar.

A partir de 1976 la literatura infantil empezó a ser promovida y vista desde una nueva perspectiva cuando Enka, empresa textilera de Colombia, lanzó el Premio Enka de Literatura Infantil Colombiana que motivó a autores de largo aliento ${ }^{2}$ a que escribieran para niños. Otra iniciativa importante fue el Primer Seminario sobre edición de libros infantiles y juveniles organizado por el CERLAL ${ }^{3}$ en 1979. 
Entre 1983 y 1988 la producción y publicación de literatura infantil colombiana fue superior a la del periodo 1950-1980. La sociedad estaba cambiando y muchos padres con mayor poder adquisitivo y un nivel educativo superior al de sus predecesores, se convirtieron en compradores de libros para niños como elementos de ocio, diversión y aprendizaje para sus hijos. Mientras los currículos escolares reconocían la literatura infantil como género literario, los medios de comunicación se dirigían a los niños de forma insistente, forjándolos como consumidores de mercancías específicas para ellos (Castrillón 1988).

Por lo demás, la industria editorial y gráfica colombiana se encontraba en un punto cumbre de su desarrollo. El número de títulos publicados en el país se triplicó entre 1980 y 1985 (Pombo 1994) como resultado del desarrollo de empresas gráficas y editoriales con importante capacidad empresarial, la existencia de un marco legal favorable y el mejoramiento de la red de librerías, la creación de instituciones de promoción de lectura, bibliotecas públicas y el desarrollo de nuevos canales de venta masiva, como las grandes superficies.

Editoriales como Bedout, Susaeta, Colina, Salvat, Círculo de Lectores, Tres Culturas, Presencia, Oveja Negra, SM, Alfaguara y, de manera destacable Norma, Carlos Valencia y Kapelusz - Barco de Papel encontraron en los primeros lectores (y en la escuela) un mercado infalible.

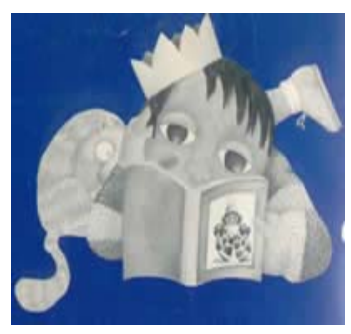

(C) Maria Paula Bolaños. F 2007.

Carlos Valencia Editores, con Margarita Valencia a la cabeza, fue la primera editorial colombiana en tener una colección de literatura infantil al comprar los derechos de las obras ganadoras del Premio Enka. Esta colección, además de tener una identidad gráfica de cubierta e interiores, tenía una intención editorial basada en dos premisas: la búsqueda de autores que escribieran para niños y la creación de ilustraciones propias para cada uno de los libros. 


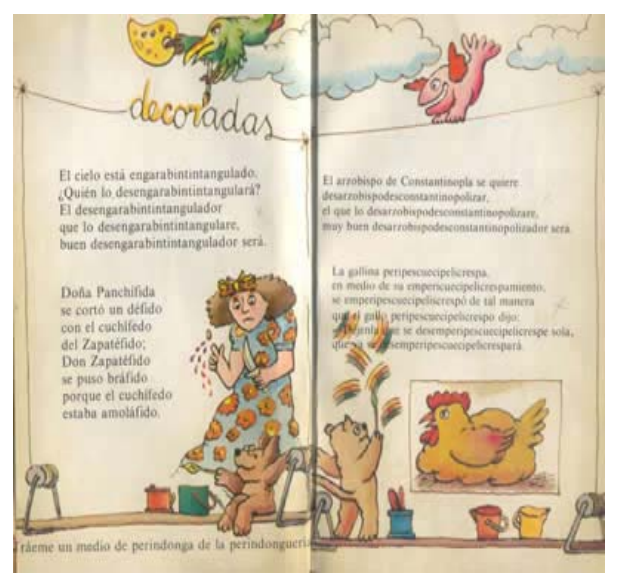

(C) G. Calvi. Del libro Traba la lengua, lengua la traba, de C. Ruiz (textos) y G. Calvi (il..).

Bogotá: Barco de Papel, 1984.

Posteriormente Valencia creó la "Colección OA" para niños, una colección íntegramente concebida en la que predominaban los libros ilustrados con tapa rústica y gran formato, con un espacio más amplio para las ilustraciones. Esta colección se inclinó a la publicación de libros en donde las ilustraciones fueran parte determinante en el texto, promoviendo un carácter secuencial imagen-texto. Los ilustradores debían plasmar momentos específicos que eran seleccionados por el director de arte de acuerdo con el carácter y la expresividad de la historia. La concepción sobre la imagen que debería acompañar un texto fue otro de los aportes importantes de esta editorial. El trabajo era cuidadoso y dependía de la dirección de Camilo Umaña, quien establecía para cada texto un tratamiento distinto de la imagen.

El siguiente impulso editorial significativo vino de la editorial argentina Kapelusz - Barco de Papel que, a partir de 1984 y con Silvia Castrillón como directora editorial, Diana Castellanos como directora de arte y Gian Calvi como asesor gráfico, publicó varios libros ilustrados de tradición oral en la colección "Postre de letras".

El trabajo de ilustración y diagramación de estos libros fue innovador: color, formato pequeño y tapa dura, el texto y las imágenes se complementaban, aunque no lo suficiente como para catalogarse como libros álbum. La tipografía por fin fue considerada un elemento de expresión narrativa, así que, con distintos tamaños en las letras y las frases intercaladas con las imágenes, se compusieron páginas dinámicas.

A pesar de este impulso editorial, la noción de libro álbum era aún incipiente, al contrario que en Venezuela, donde Ekaré fue la abanderada (para este país y para América Latina) de este género en construcción. De acuerdo con Verónica Uribe, fundadora y editora de Ekaré, uno de los grandes aportes de esta editorial fue 
La valoración del rol de editor de libros para niños, concepto que no existía en América Latina ni en España. Fuimos la primera editorial que tuvo editores especializados y directores de arte [...] Insistimos en el rescate de lo latinoamericano, tanto en los textos como en las imágenes, en la necesidad de recrear a nivel ficcional una realidad que estaba ausente de los libros para niños del continente: los pobres, la población mestiza, los marginados, el paisaje tropical, el paisaje urbano (Viva voce).

\section{La formación de ilustradores como autores}

Los primeros libros-álbum colombianos surgieron en la década de 1980 como resultado de varios componentes: el fortalecimiento de la industria editorial y el desarrollo de la gráfica, la consolidación de la figura de un editor de literatura infantil, la apertura de un mercado para el libro infantil, el desarrollo de la industria gráfica, el reconocimiento de la literatura infantil como género y, rasgo muy importante, la valoración del ilustrador como autor del libro.

Los artistas plásticos que solían ilustrar los libros antes de esta década eran magníficos interpretadores de los textos, sin embargo, faltaba contundencia en la comunicación, por lo que sus imágenes eran principalmente complementarias u ornamentales. Con el auge de la literatura infantil en los ochenta, el oficio de ilustradores y diseñadores se profesionalizó y consolidó.

En 1983, CERLALC y ACLIJ ${ }^{4}$ abrieron el Curso subregional sobre diseño $e$ ilustración del libro, dictado por el ilustrador brasileño Gian Calvi. Este curso sugería que la ilustración debía ser una prolongación del texto y a su vez ir más allá, hasta no poder disociarse del mismo. "El texto del libro infantil debe tener un sentido de imagen y la ilustración debe ser tan rica en contenido, que llegue a convertirse en un texto" (Calvi 1983, s/n). Promovía también la búsqueda de un sello personal del diseñador y el ilustrador, que debía ir de la mano de una creatividad correspondiente a unas características socioculturales definidas libres de estereotipos. Este curso generó una reflexión alrededor de la ilustración, de lo que con ella se quería expresar y de las tendencias preponderantes en ese momento.

Además se promovió la creación de la figura del director de arte en el ámbito editorial, como una persona encargada de la dirección gráfica de una colección y de cada libro, que tuviera a cargo - siempre con el apoyo del director editorial - la selección del ilustrador, su acompañamiento para el desarrollo de las ilustraciones, y la coordinación de los diseñadores en cuanto a la organización texto-imagen. 


\section{Haciendo camino. El primer libro-álbum}

El boom editorial y el surgimiento de ilustradores especialmente interesados en la literatura infantil dieron lugar a las colecciones de libros ilustrados que sin duda serían la cuna del libro-álbum colombiano. Fue en la editorial Norma donde se gestaron los primeros libros cuya narrativa pasaría del monopolio de la escritura al de la imagen.

Tras el Seminario de Edición de Libros para Niños, promovido por el CERLALC, Editorial Norma contrató a Silvia Castrillón - quien fuera editora de Kapelusz-Barco de Papel y fundadora de ACLIJ - como directora editorial de literatura infantil. Con un conocimiento amplísimo de este tema, y la constante reflexión sobre los libros para niños, Castrillón abordó el libro infantil desde una perspectiva distinta y originó los primeros libros álbum pensados, ilustrados y editados en Colombia.

De acuerdo con Castrillón (2007),

En la década de los ochenta se pensó que el editor de libros para niños tendría que ser una persona específica, con unos roles determinados dentro de todo ese circuito editorial. Además, se juzgó la edición de libros para niños como algo importante: el niño empezó a considerarse un nicho de mercado para todo tipo de productos: comida, ropa, juguetes y libros distintos a los escolares. Ahí arrancó una nueva etapa en la edición de libros para niños en Colombia y fue en esa etapa cuando el diseño de una colección o del libro individual empezó a hacerse en el país. (Viva voce)

Esto facilitó que se conformara un equipo editorial (editor, director de arte, autores, diseñadores e ilustradores) que entre 1986 y 1987 trabajó en la creación de colecciones como "Mira, ¿qué es esto?”, para bebés; "Un mundo de cosas para mirar" y "Chigüiro" para prelectores; "Abra palabra" para primeros lectores y "Torre de papel” para lectores avanzados.

En la colección “Mira, ¿qué es esto?” aparecieron los primeros libros para bebés hechos en Colombia. Con pequeño formato, prevalecía la ilustración de elementos del entorno del bebé y la palabra correspondiente al objeto. Se trataba de una serie expositiva, más informativa que narrativa.

La colección "Abra palabra" enfatizó en la tradición oral proponiendo una diagramación especial, un tipo de tipografía apta y legible para los niños, ilustraciones con imágenes divertidas y cercanas a lo que diariamente veían en las ciudades o en el campo. En esta colección se destacan El mico y el loro y La casa que Juan construyó, coplas inglesas adaptadas al entorno nacional a partir del lenguaje, el humor y, especialmente, desde la ilustración. 


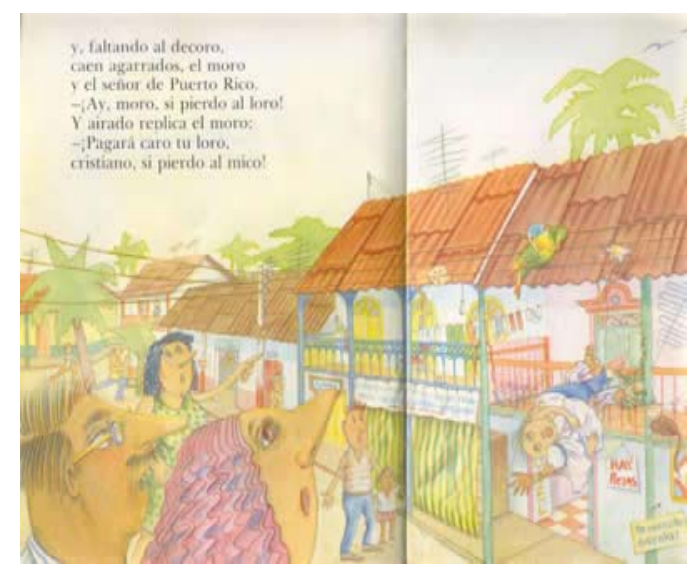

(C) D.Castellanos,.Del libro 6. Página interna de $E l$ mico y el loro, Bogotá: Norma,1987. Ilustró Diana Castellanos.

El mico y el loro causó tal controversia que no se reimprimió por su contenido político y violento. El libro fue magníficamente ilustrado por Diana Castellanos, quien ubicó la historia en un pueblo de la costa colombiana brindándole todas sus características gráficas.

La casa que Juan construyó se "nacionalizó" al incluir imágenes de la cotidianeidad urbana de los personajes y paisajes populares bogotanos. Su adaptación e ilustración estuvo a cargo de Diana Castellanos quien, con un estilo similar al de El mico y el loro, propuso la imagen desde un popular barrio bogotano. "Cada página contiene multitud de detalles para ver y volver a ver, pues siempre se podrá hallar algo en que antes no se había reparado", dice Castellanos (Viva voce, 2007).

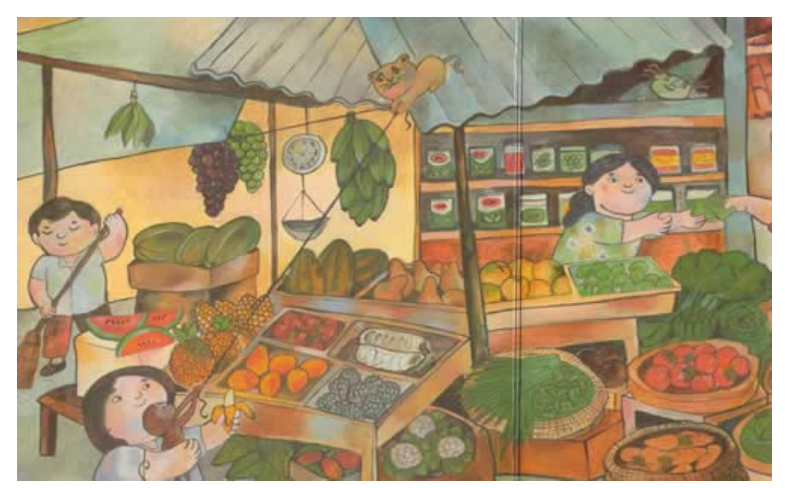

(C) Alekos. Del libro El mercado, Bogotá: Norma, 1986.

Estos libros poseen una recreación visual particularmente innovadora y de alguna manera generan un diálogo entre el texto y las imágenes, dándole un sentido mucho más local a las palabras. Aún así las ilustraciones no cuentan una historia por sí mismas, sino que plasman las acciones de manera idéntica a como son contadas en el texto. 
La colección "Un mundo de cosas para mirar" promovió una secuencia visual no estrictamente narrativa, pero con múltiples detalles que generaban las primeras lecturas visuales en los más pequeños.

La colección Chigüiro, de Ivar Da Coll, abrió el camino del libro álbum en Colombia. Según sostiene este autor e ilustrador:

Fue idea de Silvia (Castrillón) buscar alguien que creara un personaje animal, preferiblemente de la fauna nuestra, que contara una historia en imágenes. La idea, el embrión, es de Silvia, yo lo desarrollé con el Chigüiro. Y la verdad, sí fue un trabajo pionero, fue uno de los primeros libros en imágenes (en Colombia), bien estructurados (Da Coll, Viva voce, 2007).

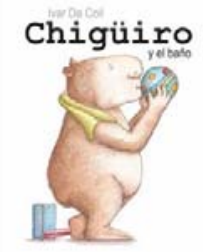

\footnotetext{
(C) Da Coll. Chigüiro, uno de los personajes entrañables de la literatura infantil colombiana.
}

"Chigüiro", que empezó siendo la historia de un personaje contada en veinticuatro cuadros, se convirtió en la primera colección de libros álbum netamente colombianos. Mediante veinticuatro ilustraciones por libro, Da Coll desarrolló varias historias sin texto, con tal fortaleza en la imagen que cualquier texto sería innecesario

Trabajé en los artes finales de Chigüiro muy duro, durante siete u ocho horas diarias, de domingo a domingo. El personaje debía ser consistente; debía conservar el mismo color de piel, conservar una proporción adecuada con respecto a la página, y a través de los veinticuatro cuadros; debía moverse, transmitir al lector la idea de que estaba vivo: podía caminar, saltar, reír, dormir, y después de todas estas acciones, siempre, siempre, ser el mismo Chigüiro. (Da Coll, Viva voce, 2007)

La narración de imágenes sin palabras es una de las formas más complicadas del libro álbum. Según Nikolajeva y Scott (2006: 10) la tensión entre imágenes alerta al lector de la relación entre la narrativa lineal y el aparente aspecto estático de las imágenes, sosteniendo una reevaluación de su interacción. Así, la colección “Chigüiro” cuenta historias redondas y coherentes que generan la curiosidad del lector a partir de elementos temporales, de movimiento, dramáticos y estéticos que dan lugar a la lectura de imágenes sin necesidad de palabras.

Con la salida de Castrillón de Norma, la mayor parte de las colecciones infantiles desaparecieron, sólo quedó "Torre de Papel” y los álbumes de Da Coll 
empezaron a formar parte de la nueva colección "Buenas noches" de esta misma editorial.

Otras editoriales también clausuraron colecciones de libros ilustrados, se concentraron en elaborar un catálogo de cuentos cortos y novelas ilustradas para un «Plan Lector», es decir, para los libros de literatura infantil que pedían los colegios. Los libros ilustrados a color, de gran formato, y los libros álbum fueron desplazados y, una vez más, la tendencia en cuanto a este género fue la de la importación de títulos.

\section{Años noventa y panorama actual}

Las editoriales colombianas produjeron libros para niños desde la base del «Plan Lector» escolar, con una definición principalmente comercial, de forma que el auge de la literatura infantil de los ochenta se transforma. Prevalecen así las necesidades pedagógicas: la literatura sacrifica su calidad en favor de lo que el docente necesita en el salón de clases, es decir, de lo que los padres comprarán como un requerimiento escolar más. Así, los criterios editoriales se definen por requerimientos comerciales, que casi nunca incluyen al libro álbum ni a los autores locales. El temor a arriesgar domina. En los noventa Norma y Alfaguara se fortalecen en el Plan Lector y Panamericana Editorial crece y apuesta por los autores locales, aunque sin grandes aportes.

Norma compra los derechos editoriales de Disney, Barbie, Barnie, Franklin y Elmer, que dominan las grandes superficies y se convierten en la primera opción de compra para muchos padres.

Panamericana Editorial crece y se fortalece en los noventa. En 2009 cuenta ya con más de 30 colecciones de literatura infantil sin un sello editorial definido y notable irregularidad en la calidad literaria. Panamericana retoma la Colección OA de Valencia Editores, pero los nuevos títulos no tienen la misma contundencia que los originales.

Desde la década de los noventa hasta la actualidad hemos notado que las editoriales temen arriesgar, lo que repercute en productos de similar calidad.

No hay mucho espacio para un editor con ideas, creativo, que opine, que piense o que quiera explorar, ahora no es fácil y manda todo el mundo: los maestros, los padres, el mercado, todo menos los criterios que deberían mandar que son la calidad, la diversión, el gozo, la creación, la efervescencia, la posibilidad de mostrar una cosa desde un punto de vista que nadie ha visto. (Valencia, Viva voce, 2007)

Otra dificultad está relacionada con el comportamiento lector ya que, de acuerdo con Ramírez (2007: 127), el 60\% de los colombianos mayores de 12 años afirma no leer 
libros y el promedio de libros leídos al año es de 4,2. "Si a esta cifra se le resta la lectura de textos escolares (incluida en el registro), el panorama resulta desolador" (Viva voce, 2007), concluye. De acuerdo con el análisis publicado en el Anuario de la Literatura Infantil y Juvenil de Editorial SM:

Los títulos nuevos de autores colombianos (de literatura infantil) durante 2006 no debieron superar los 50 (incluyendo reimpresiones de los autores reconocidos). Las editoriales de LIJ que editan en Colombia han preferido asentar sus fondos con autores extranjeros y no parecen interesadas en desarrollar catálogos de autores locales. Hay un círculo de culpas al respecto, que va de la carencia de obras de valor (dicen los editores) al desinterés de los editores por los escritores nativos (dicen los autores). (2007: 130)

Ante la crisis lectora, organismos estatales e independientes crean y fortalecen programas, proyectos y actividades de promoción de lectura. Nunca antes hubo un auge tan fuerte en la promoción de la lectura en Colombia como en este momento de crisis lectora. Finalmente, con el presidente Uribe, el gobierno promovió un Plan Nacional de Lectura y Bibliotecas en 2004. El distrito capital, por su parte, estableció políticas de lectura y escritura y por primera vez en la historia de la ciudad se realizó la Primera Feria del Libro Infantil en 2007.

A pesar de esto, las perspectivas para el libro-álbum en la década del 2000 en Colombia fueron esperanzadoras, el clima editorial para el libro infantil mejora y el hecho más significativo es quizás la apertura de nuevas editoriales, como Babel Libros, y de nuevas colecciones de libros álbum por parte de las editoriales tradicionales, como Norma con "Fuera de colección" y Alfaguara Infantil Colombia con "Nidos para la lectura".

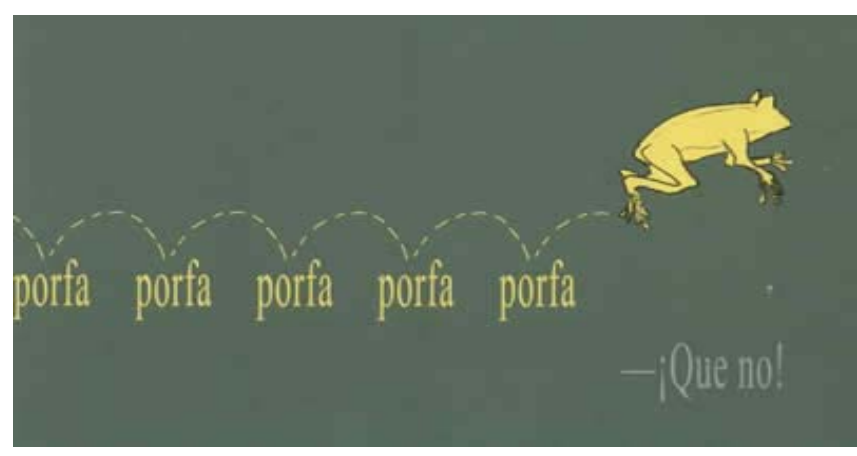

(C) Maria Paula Bolaños. Fragmento del libro Rana, Bogota: Babel, 2007.

Babel Libros es, actualmente, la única editorial colombiana dedicada exclusivamente a la publicación de libros para niños y jóvenes, dando un lugar especial a la publicación de libros-álbum. "La idea es buscar nuevos autores, nuevos ilustradores y darles un espacio de trabajo diferente al creado por unas editoriales donde creen que un libro- 
álbum es un libro grande con imágenes gigantes y el texto encima" sostiene María Osorio (Viva voce, 2007), editora de Babel. Su fondo de Babel se ha alimentado con libros de autores e ilustradores de distintas partes del mundo, y promoviendo la reedición de libros descatalogados, como la serie de "Chigüiro" y la de "Eusebio", ambas de Ivar Da Coll. Uno de los aportes más acertados y significativos de esta editorial fue la publicación de Rana, de María Paula Bolaños. De acuerdo a la definición del libro-álbum planteada por Fanuel Díaz (2007), este libro podría ser considerado el primer auténtico libro-álbum colombiano en el que hay un texto. Rana se presta a múltiples y ricas lecturas, creando un complemento perfecto e inseparable entre la imagen y el texto.

El papel de los ilustradores ha sido fundamental. La dupla colombiana Yockteng-Buitrago fue ganadora del premio internacional de libro álbum A la orilla del viento, de FCE en 2007. Este galardón fue entregado de nuevo a otro colombiano, Dipacho, en 2008. Este tipo de incentivos generan confianza tanto en los editores como en los autores e ilustradores.

\section{Para cerrar...}

Tanto la literatura infantil colombiana como la ilustración de este tipo de libros son materias relativamente nuevas en la historia de Colombia. En cuanto a la ilustración, es notable la influencia y el aporte de los artistas plásticos antes de la década de 1980, posteriormente la idea de infancia se torna más acorde a la actualidad. La infancia representada no es ya la infancia perdida y nostálgica de los artistas, sino una infancia "hacia los niños": personajes con los que ellos pueden sentirse identificados, niños contemporáneos, situaciones familiares y referentes gráficos locales.

Actualmente, ante la crisis lectora y editorial de los libros para niños, es posible encontrar esfuerzos significativos por promover hábitos lectores. El aporte de Babel Libros en la industria local ha sido significativo, con la promoción de una asociación de librerías, del Primer congreso de editores de libros infantiles de América Latina, o mediante la creación de un comité asesor de literatura infantil en la Cámara Colombiana del Libro. Cada una de estas iniciativas reúne a representantes de distintas entidades cuyo trabajo se centra en los libros para niños - ya sea la promoción, la creación, la distribución o la edición con el fin no de trabajar en competencia, sino enfocados en un mismo propósito: mejorar las posibilidades comerciales de las editoriales, las librerías y 
las distribuidoras y, por añadidura, mejorar las alternativas laborales para escritores, ilustradores y, aún mejor, ofrecer a los lectores mejores precios y libros de mejor calidad.

El desarrollo del libro álbum en Colombia ya empezó su desarrollo. Por lo pronto los ilustradores se han reorganizado con el apoyo de Fundalectura - antes ACLIJ - desde donde se ofrecen capacitaciones para conocer a fondo las distintas tendencias de la literatura infantil. Más y más personas se interesan por este género, que cada vez gana más espacio en medios de comunicación, librerías, y entre las preferencias de los lectores. El paso a seguir está en manos de las editoriales, que deberían darle un voto de confianza al libro álbum de autoría colombiana.

\section{Libros-álbum que conforman el corpus analizado}

Alekos (1986) El mercado, Bogotá: Norma.

Bolaños, M. P. (2007) Rana, Bogotá: Babel.

Buitrago, J., Yockteng, R. (2008) Camino a casa, México: FCE.

Castellanos, D. (1987) La casa que Juan construyó, Bogotá: Norma.

Castellanos, D. (1987) El mico y el loro, Bogotá: Norma.

Da Coll, I. (1987). Serie Chigüiro, Bogotá: Norma y Babel libros.

Díaz Díaz, O.; Trujillo Magnenat, S. (il.)(1967) Cuentos tricolores. Colección Mi libro ideal. Tomo 1. Bogotá: Ediciones Lerner Juveniles

Dipacho (2009) Jacinto, María y José. México: FCE.

Eastman, M.; Tejada, L. y otros (il.); (1948) El conejo Viajero, Bogotá: Editorial de la Universidad Nacional.

Fornaguera, M. (Comp); Jaramillo, L. (il.) (1980) Qué bonito baila el chulo: sobre cantas del Valle de Tenza, Bogotá: Carlos Valencia Editores.

Ruíz, C.; Alekos (il.) (1993) Tocotoc: el cartero enamorado, Santa Fe de Bogotá: Atípicos.

Ruíz, C.; Calvi, G. (il.) (1984) Traba la lengua, lengua la traba, Bogotá: Ediciones el Barco de Papel.

\section{Referencias Bibliográficas}

Calvi, G. (1983) Algunas ideas para estimular la creatividad. Primera versión, julio 15 de 1983. Documento del Curso subregional sobre diseño e ilustración del libro, Bogotá, 7-18 de noviembre.

Castrillón, S. (1988) "Panorama actual de la literatura infantil en Colombia". Documento a petición del CERLALC.

Cerlal (1979) Documento Seminario sobre Edición de Libros Infantiles y Juveniles, Bogotá, febrero.

Cerlalc (1983) Curso audiovisual. El diseño y la ilustración del libro, Bogotá: Cerlalc.

Colomer, T. (2002) Siete llaves para valorar las historias infantiles, Madrid: Fundación Germán Sánchez Ruipérez. 
Da Coll, I. (2009) Memorias de un chigüiro. En: http://www.pangea.org/gretel-

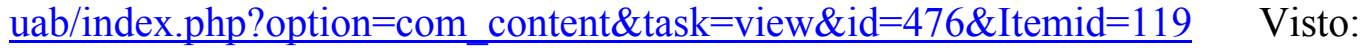
enero 6 de 2010.

Díaz, F. (2001) Concurso Enka. Revista Latinoamericana de Literatura Infantil y Juvenil, 13, Bogotá: enero - junio.

(2007) Leer y mirar el libro álbum: ¿Un género en construcción? Bogotá: Grupo Editorial Norma.

Entrevista realizada por la autora a Beatriz Elena Robledo, marzo 22 de 2007. Viva voce.

Entrevista realizada a Camilo Umaña, julio 23 de 2007. Viva voce.

Entrevista realizada por la autora a Diana Castellanos, mayo 18 de 2007. Viva voce.

Entrevista realizada por la autora a Ivar Da Coll, julio 17 de 2007. Viva voce.

Entrevista realizada por la Margarita Valencia, junio 15 de 2007. Viva voce.

Entrevista realizada por la autora a María Osorio, agosto 1 de 2007. Viva voce.

Entrevista realizada por la autora Silvia Castrillón, junio 27 de 2007. Viva voce.

Nikolajeva, M. y Scott, C. (2006) How Picturebooks Works, London: Roudledge.

Pombo, S. (1994) Mito o realidad del libro. Conferencias realizadas durante el Seminario Internacional Mito o Realidad del Libro. Santa Fe de Bogotá: Cerlalc, Colcultura, Aseuc.

Ramírez, C. (2007) Lectura y LIJ en Colombia 2006. Anuario sobre el libro infantil y juvenil 2007, Madrid: SM.

Silva-Díaz, M. C. (2006) La función de la imagen en el álbum. Peonza: Revista de literatura infantil y juvenil, 75-76. En "Compartiendo el libro álbum", Laboratorio Internacional Cubriendo Lectores. Santiago de Chile: Centro Cultural de España.

Sipe, L. (2008) Postmodern Picturebooks. New York: Routledge Education.

\footnotetext{
${ }^{1}$ El presente artículo forma parte del trabajo de grado Panorama histórico del libro ilustrado de literatura infantil colombiana para el Master en literatura y libros para niños y jóvenes de la Universidad Autónoma de Barcelona.

2 Como Jairo Aníbal Niño, Celso Román, Irene Vasco o Triunfo Arciniegas, autores aún vigentes.

${ }^{3}$ Centro Regional para el Fomento al Libro en América Latina, organismo internacional respaldado por la UNESCO que promueve la organización del sector del libro, la formación editorial y la promoción de la lectura.

${ }^{4}$ Asociación Colombiana para el Libro Infantil y Juvenil.
} 